\title{
Accelerated Bleaching of Cotton Material with Hydrogen Peroxide
}

\author{
Abdul SB* and Narendra G \\ Center for Textile functions, NMIMS University, Shirpur District, Dhule, India
}

\begin{abstract}
Nowadays, consumers increasingly demand more environmentally friendly products. This also affects the textile industry, and thus, aspects such as control of water, energy and chemicals consumption should be taken into account in textile processes. Hydrogen peroxide $\left(\mathrm{H}_{2} \mathrm{O}_{2}\right)$ is the most widely used bleaching agent for textiles and came into use around. Hydrogen peroxide is suitable for most fibers and it can be used in a wide range of machines under different conditions. Reaction products are non-toxic and non-dangerous it is applicable in strongly alkaline medium and it requires a high temperature to give the most effective bleaching. Recent research in our laboratories has focused on the development and application of compounds that enhance the bleaching process. In this investigation in order to optimize time and temperature of bleaching process various experimentations were carried out, this study reveals that, a) an increase the temperature the rate of bleaching is increases \& correspondingly reduction in process time. b) An increase in concentration of $\left(\mathrm{H}_{2} \mathrm{O}_{2}\right)$ whiteness and weight loss is increases c) Hardness of water inversely proportional to whiteness \& directly proportional to weight loss. d) The concentration of peroxide stabilizer is inversely proportional to the whiteness and directly proportional to weight loss.
\end{abstract}

Keywords: Optimization; Time; Temperature; Hydrogen peroxide; Whiteness; Weight loss \%

\section{Introduction}

The natural fiber and fabrics even after scouring still contain naturally occurring coloring matter. This yellowish and brown discoloration may be related to flavones pigment of the cotton flower. The climate, soil, drought and frost can also cause various degrees of yellowness. Tips of leaves or stalks coming in contact with the moist ball after opening will cause dark spots and discoloration.

Discoloration may also come from dirt, dust, and insects or from harvesting or processing equipment in the form of oils and greases. The object of bleaching is to produce white fabrics by destroying the colorings matter with the help of bleaching agents with minimum degradation of the fiber [1]. The bleaching agents either oxidize or reduce the coloring matter which is washed out and whiteness thus obtained is of permanent nature. Chemical bleaching of textile fibers is further aided by addition of optical brighteners.

The later stage of twentieth century the time required for bleaching dropped steadily from months to days to hours. Now-a-days, manpower required for average plant is declined considerably and the cost of bleached finished product is also reduced.

This technical break-through will continue in the future also and will reduce the cost of bleaching further. In the present experimentation efforts were made to optimized time, temperature and concentration of hydrogen peroxide, whiteness, weight loss of substrate [2].

\section{Major objectives of investigation}

1. Analyze Effects of the chemicals used in cotton bleaching process.

2. Minimized the time of bleaching process.

3. Optimize the percentages of chemicals are required for bleaching process.

4. Maximize whiteness and minimized the weight loss of bleaching process.

\section{Mechanism of peroxide bleaching}

Though hydrogen peroxide is stable in acidic medium, but bleaching occurs by the addition of alkali or by increased temperature. Hydrogen peroxide liberates per hydroxyl ion $\left(\mathrm{HO}^{2-}\right)$ in aqueous medium and chemically behaves like a weak dibasic acid. The per-hydroxyl is highly unstable and in the presence of oxidizable substance (coloured impurities in cotton), it is decomposed and thus bleaching action takes place. Sodium hydroxide activates hydrogen peroxide because $\mathrm{H}$ ion is neutralized by alkali which is favorable for liberation of $\mathrm{O}_{2}$.

$$
\begin{gathered}
\mathrm{H}_{2} \mathrm{O}_{2} \sim \mathrm{H}++\mathrm{HO}^{2-} \\
\mathrm{H}_{2} \mathrm{O}_{2} \sim \sim \mathrm{H}++\mathrm{HO}^{2-} \mathrm{OH}->\mathrm{HO}^{2-}+\mathrm{H}_{2} \mathrm{O}
\end{gathered}
$$

However, at higher $\mathrm{pH}$ (above 10.8) the liberation of $\mathrm{HO}^{2-}$ ion is so rapid that it becomes unstable with the formation of oxygen gas which has no bleaching property.

If the rate of decomposition is very high, the unutilized $\mathrm{HO}^{2-}$ may damage the fiber. A safe and optimum $\mathrm{pH}$ for cotton bleaching lies in 10.5 to 10.8 where as the rate of evolution of per hydroxyl ion is equal to the rate of consumption (for bleaching). At higher $\mathrm{pH}$, hydrogen peroxide is not stable and hence a stabilizer is frequently added in the bleaching bath [3].

\section{Material and Method}

The material of 24's count single jerky 180 gsm fabrics obtained from commercial dyeing unit PSSGL Pvt. Ltd. Shirpur. An experiment is planned to optimize time and temperature of bleaching process, the bleaching process were carried out at different dwell time by varying temperature $100^{\circ} \mathrm{C}$ and $110^{\circ} \mathrm{C}$ and analyze the whiteness and weight loss of given substrate. Laboratory base bleaching process carried out on $5 \mathrm{gm}$ of fabric, keeping liquor to goods ratio1:10. Whiteness of fabric

*Corresponding author: Abdul SB, Center for Textile functions, NMIMS University, Shirpur District, Dhule, India, E-mail: abdulsalaambagwan@gmail.com

Received June 29, 2013; Accepted September 13, 2013; Published September 20, 2013

Citation: Abdul SB, Narendra G (2013) Accelerated Bleaching of Cotton Material with Hydrogen Peroxide. J Textile Sci Eng 3: 140. doi:10.4172/2165-8064.1000140

Copyright: (C) 2013 Abdul SB, et al. This is an open-access article distributed under the terms of the Creative Commons Attribution License, which permits unrestricted use, distribution, and reproduction in any medium, provided the original author and source are credited. 
analyzed under spectrophotometer and weight loss were analyzed by taking weights of substrate before and after the bleaching process [4].

Digital PH Meter: A digital pH/Temperature meter was used with a combination of glass electrode.

Whiteness Measurement: The CIE Whiteness Index value (CIE WI) was determined for the bleached fabric using AATCC Test method. The whiteness was measured using a Data color Spectra flash SF 600X with the following setting; illuminants D-65 [5].

\section{Following chemicals used for bleaching process}

1. Hydrogen Peroxide

2. Peroxide stabilizer (Lenapex HPST)

3. Demineralising Agent (Invatex $S W$ )

4. Caustic soda (Sodium Hydroxide).

5. Wetting Agent (Perlavin EPO).

6. Calcium Chloride.

7. Acetic Acid.

8. Sodium Silicate.

\section{Results and Discussions}

The purpose of this study was to explore the possibility of bleaching cotton fabric by hydrogen peroxide with varying temperature and time and analyze the effects on weight loss and whiteness and to achieve an acceptable degree of whiteness (CIE whiteness index 75) with minimum loss. Standard Recipe:

$\begin{array}{lll}\text { Wetting agent } & = & 1.00 \mathrm{gpl} \\ \text { Peroxide stabilizer } & = & 0.25 \mathrm{gpl} \\ \text { Demineralising agent } & = & 0.30 \mathrm{gpl} \\ \text { Caustic soda } & = & 3.00 \mathrm{gpl} \\ \text { Hydrogen peroxide } & = & 2.00 \mathrm{gpl}\end{array}$

Effect of process time of bleaching on whiteness and weight loss

From Figures 1,2 and Table 1 it was observed that at $100^{\circ} \mathrm{C}$ temperature and dwell time of process increases 10,15 and 20 minutes, the whiteness and weight loss is increases respectively but wax, impurities and natural coloring matter not completely removed from the substrate and with standard recipe at $110^{\circ} \mathrm{C}$ with $20 \mathrm{~min}$ dwell time whiteness increases and weight loss also increases. Among the all Recipes, Recipe III shows optimum whiteness and weight loss as standard. In general, the time of bleaching is inversely proportional to

\section{Whiteness(\%)}

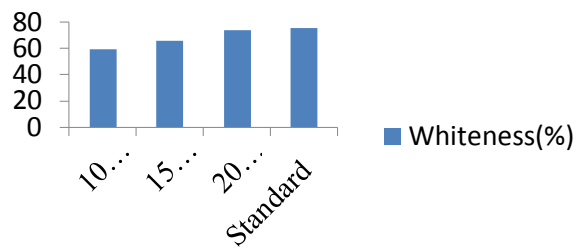

Figure 1: Effect of process time of bleaching on whiteness.

\section{Weight Loss $(\%)$}

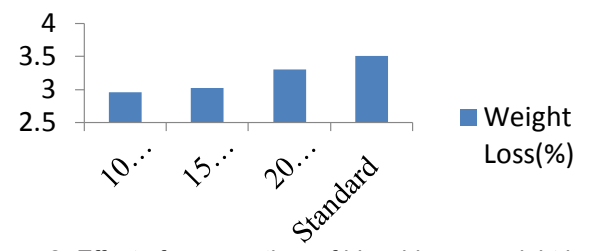

Figure 2: Effect of process time of bleaching on weight loss.

\begin{tabular}{|l|l|l|l|l|l|}
\hline Sr No. & Parameters & Temperature & Time & $\begin{array}{l}\text { Whiteness } \\
\text { (\%) }\end{array}$ & $\begin{array}{l}\text { Weight } \\
\text { Loss (\%) }\end{array}$ \\
\hline 1. & Standard & $110^{\circ} \mathrm{C}$ & 20 minutes & 75.00 & 3.50 \\
\hline 2. & Standard & $100^{\circ} \mathrm{C}$ & 10 minutes & 58.80 & 2.95 \\
\hline 3 & Standard & $100^{\circ} \mathrm{C}$ & 15 minutes & 65.40 & 3.02 \\
\hline 4 & Standard & $100^{\circ} \mathrm{C}$ & 20 minutes & 73.81 & 3.30 \\
\hline
\end{tabular}

Table 1: Shows the effect Standard recipe varying with temperature and time for optimizing whiteness and weight loss $\%$.

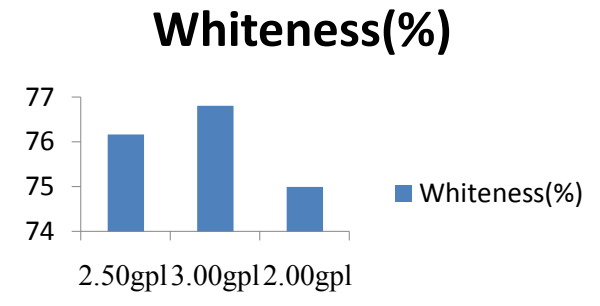

Figure 3: Effect of concentration of hydrogen peroxide on whiteness and weight loss \%.

\section{Weight Loss(\%)}

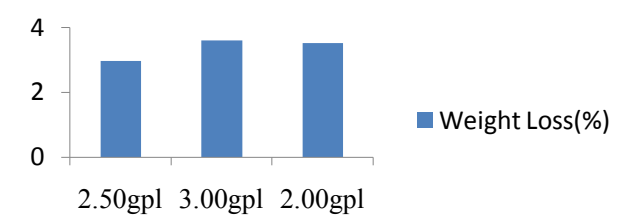

Figure 4: Effect of concentration of hydrogen peroxide on weight loss $\%$

the temperature of the bleaching bath [6].

Effect of concentration of hydrogen peroxide on whiteness and weight loss $\%$

In order to reduce the time of bleaching process, increasing concentration of Hydrogen peroxide \& analyzes the effects on given substrate and compare with standard process.

From Figures 3,4 and Tables 2,3 it was observed that, an increasing concentration of hydrogen peroxide with temperatures reducing the dwell time of the bleaching process. Whiteness and weight loss of substrate is increases. Recipe-II recorded high Whiteness \& weight loss but not severe damage to the fabric. Among the all recipes with standard, Recipe-I show optimum result compare to standard. As concentration increases from $2 \mathrm{gpl}$ to $2.5 \mathrm{gpl}, 3 \mathrm{gpl}$ whiteness increases and weight loss is also increases. But recipe-I recorded optimum whiteness and weight 


\begin{tabular}{|c|c|c|c|c|c|c|}
\hline $\begin{array}{c}\text { Sr } \\
\text { No. }\end{array}$ & $\begin{array}{c}\text { Chemicals } \\
\text { used in } \\
\text { standard } \\
\text { recipes }\end{array}$ & Concentration & Temperature & Time & Whiteness & $\begin{array}{l}\text { Weight } \\
\text { loss \% }\end{array}$ \\
\hline 1 & Wetting agent & $1.00 \mathrm{gpl}$ & $110^{\circ} \mathrm{C}$ & $20 \mathrm{~min}$ & 75.00 & 3.50 \\
\hline 2 & $\begin{array}{c}\text { Peroxide } \\
\text { stabilizer }\end{array}$ & $0.25 \mathrm{gpl}$ & $110^{\circ} \mathrm{C}$ & $20 \mathrm{~min}$ & & \\
\hline 3 & $\begin{array}{c}\text { Demineralising } \\
\text { agent }\end{array}$ & $0.30 \mathrm{gpl}$ & $110^{\circ} \mathrm{C}$ & $20 \mathrm{~min}$ & & \\
\hline 4 & $\begin{array}{c}\text { Caustic soda } \\
\text { Hydrogen } \\
\text { peroxide }\end{array}$ & $2.00 \mathrm{gpl}$ & $110^{\circ} \mathrm{C}$ & $20 \mathrm{~min}$ & & \\
\hline 5 & $2.00 \mathrm{gpl}$ & $110^{\circ} \mathrm{C}$ & $20 \mathrm{~min}$ & & \\
\hline
\end{tabular}

Table 2: Shows the effect of standard recipe on whiteness and weight loss \%.

\begin{tabular}{|c|c|c|c|c|c|c|}
\hline Sr No. & $\begin{array}{c}\text { Recipes } \\
\text { used }\end{array}$ & $\begin{array}{c}\text { Concentration } \\
\text { Of } \mathbf{H}_{\mathbf{2}} \mathbf{O}_{\mathbf{2}} \mathbf{( g p l )}\end{array}$ & Temperature & Time & $\begin{array}{c}\text { Whiteness } \\
\text { (\%) }\end{array}$ & $\begin{array}{c}\text { Weight } \\
\text { Loss (\%) }\end{array}$ \\
\hline 1. & Standard & 2.00 & $110^{\circ} \mathrm{C}$ & 20 minutes & 75.00 & 3.50 \\
\hline 2. & Standard & 2.50 & $100^{\circ} \mathrm{C}$ & 15 minutes & 76.16 & 2.95 \\
\hline 3 & Standard & 3.00 & $100^{\circ} \mathrm{C}$ & 15 minutes & 76.80 & 3.60 \\
\hline
\end{tabular}

Table 3: Effect of concentration of hydrogen Peroxide on whiteness and weight loss.

\begin{tabular}{|c|c|c|c|}
\hline Sr No. & $\begin{array}{c}\text { Hardness Of Water } \\
\text { ( ppm ) }\end{array}$ & $\begin{array}{c}\text { Whiteness } \\
\text { (\%) }\end{array}$ & Weight Loss (\%) \\
\hline 1 & 20 & 68.54 & 3.50 \\
\hline 2 & 50 & 66.39 & 3.60 \\
\hline 3 & 100 & 66.63 & 3.70 \\
\hline 4 & 200 & 65.39 & 3.80 \\
\hline
\end{tabular}

Table 4: Effects hardness of water on whiteness and weight loss.

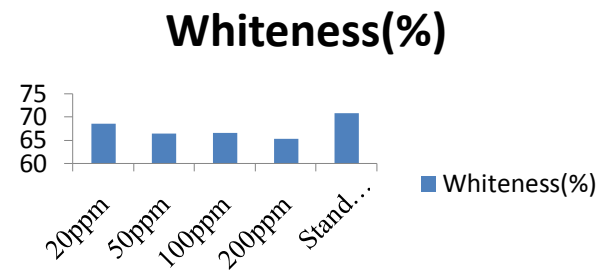

Figure 5: Effects hardness of water on whiteness and weight loss.

loss. The time required to bleach with hydrogen peroxide depends on temperature, class of fiber and equipment used for bleaching. In general, as increases the concentration of hydrogen peroxide the rate of bleaching is increases \& correspondingly whiteness increases and weight loss decreases and process time reduced. At higher temperature and process dwell time increases leads to increases weight loss.

\section{Effects hardness of water on whiteness and weight loss}

For this experimentation, Different ppm of hard water and Standard recipes without Demineralising agent, were used, Condition used were-Temperature $=100^{\circ} \mathrm{C}$ and Time $=20$ minutes and analyzing effects hardness of water on whiteness and weight loss.

From Table 4 and Figures 5,6 it was observed that When hardness of water increases $20 \mathrm{ppm}$ to $200 \mathrm{ppm}$ weight loss in the cotton substrate is increases and whiteness decreases. Among the all recipes $200 \mathrm{ppm}$ shows high weight loss and low whiteness that is due to hardness of water increases, rate of peroxide decomposition are increases. In general it was observed that as hardness of water inversely proportional to whiteness \& directly proportional to weight loss.
Effect of concentration of peroxide stabilizer on whiteness and weight loss keeping temperature constant and compare with standard

In this experimentation Standard recipes were used but concentration of peroxide stabilizer changed and analyzes the whiteness and weight loss.

Figures 7,8 and Table 5 it was observed that, an increasing concentration of stabilizer keeping temperature and time as constant, with increases concentration of peroxide stabilizer, from 0.20 to $0.35 \mathrm{gpl}$ whiteness and weight loss of cotton substrate is increases consistently. Among all the recipes from I to V. Standard recipes show optimum whiteness and weight loss. In general, the concentration of peroxide stabilizer is directly proportional to the whiteness and weight loss.

Effect of concentration of peroxide stabilizer (sodium silicates) on whiteness and weight loss

For this experimentation, standard recipes were used but concentration of stabilizer changed and analyze the effect on cotton substrate Condition for all recipes-Temperature $=100^{\circ} \mathrm{C}$ Time $=20$ minutes.

From Table 6 and Figures 9, 10 it was observed that Concentration Sodium Silicate stabilizer increases from $0.1 \mathrm{gpl}, 0.2 \mathrm{gpl}$ and 0.3

\section{Weight Loss(\%)}

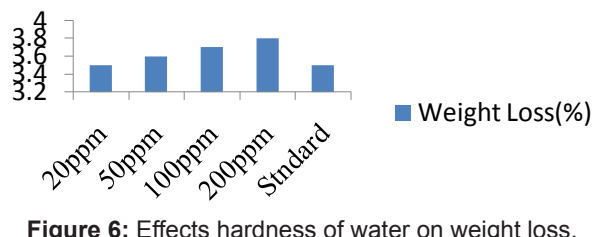

Figure 6: Effects hardness of water on weight loss.

\section{Whiteness(\%)}

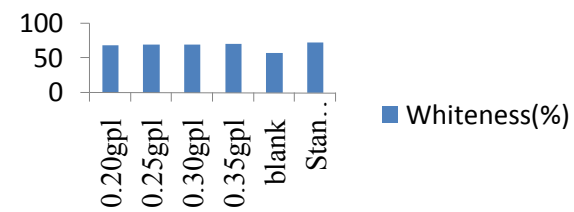

Figure 7: Effect of concentration of peroxide stabilizer on whiteness and weight loss keeping temperature constant and compare with standard

\section{Weight Loss(\%)}

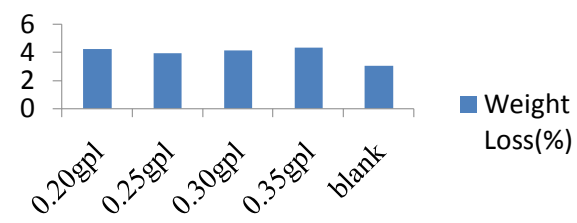

Figure 8: Effect of concentration of peroxide stabilizer on weight loss keeping temperature constant and compare with standard. 


\begin{tabular}{|c|c|c|c|c|c|c|}
\hline $\begin{array}{c}\text { Sr } \\
\text { No. }\end{array}$ & Parameters & $\begin{array}{c}\text { Concentration } \\
\text { Of Stabilizer } \\
\text { (gpl) }\end{array}$ & Temperature & Time & $\begin{array}{c}\text { Whiteness } \\
\text { (\%) }\end{array}$ & $\begin{array}{c}\text { Weight } \\
\text { Loss (\%) }\end{array}$ \\
\hline 1. & $\begin{array}{c}\text { Standard } \\
\text { recipes }\end{array}$ & 0.25 & $110^{\circ} \mathrm{C}$ & 20 minutes & 72.10 & 3.50 \\
\hline 2. & I. Recipe & 0.20 & $100^{\circ} \mathrm{C}$ & 20 minutes & 68.40 & 4.20 \\
\hline 3 & II. Recipe & 0.25 & $100^{\circ} \mathrm{C}$ & 20 minutes & 68.98 & 3.91 \\
\hline 4 & III. Recipe & 0.30 & $100^{\circ} \mathrm{C}$ & 20 minutes & 69.18 & 4.10 \\
\hline 5 & IV. Recipe & 0.35 & $100^{\circ} \mathrm{C}$ & 20 minutes & 70.04 & 4.30 \\
\hline 6 & V. Recipe & 0.00 & $100^{\circ} \mathrm{C}$ & 20 minutes & 57.44 & 3.00 \\
\hline
\end{tabular}

Table 5: Effect of concentration of Peroxide Stabilizer on whiteness and weight loss keeping temperature constant and compare with standard recipes.

\begin{tabular}{|c|c|c|c|}
\hline Recipe No. & $\begin{array}{c}\text { Concentration Of Sodium } \\
\text { Silicate (gpl) }\end{array}$ & $\begin{array}{c}\text { Whiteness } \\
\mathbf{( \% )}\end{array}$ & $\begin{array}{c}\text { Weight Loss } \\
\mathbf{( \% )}\end{array}$ \\
\hline 1 & 0.10 & 70.25 & 3.60 \\
\hline 2 & 0.20 & 70.76 & 3.50 \\
\hline 3 & 0.30 & 70.52 & 3.50 \\
\hline 4 & 0.40 & 66.46 & 4.20 \\
\hline 5 & 0.50 & 65.70 & 4.40 \\
\hline Standard & 0.25 & 70.75 & 3.50 \\
\hline
\end{tabular}

Table 6: Effect of concentration of peroxide stabilizer (sodium silicates) on whiteness and weight loss.

\section{Whiteness(\%)}

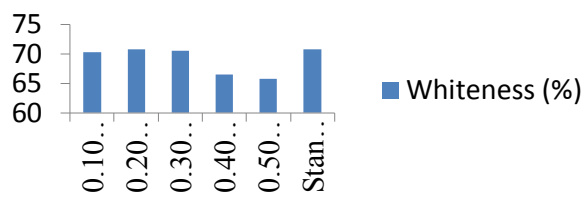

Figure 9: Effect of concentration of peroxide stabilizer (sodium silicates) on whiteness and weight loss.

\section{Weight Loss(\%)}

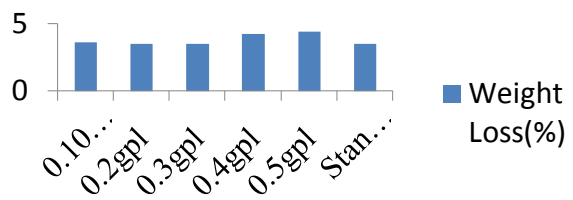

Figure 10: Effect of concentration of peroxide stabilizer (sodium silicates) on weight loss.

gpl whiteness is also increases but not as standard. But increase in concentration lead to increase considerable weight loss in bleaching process. Among the all recipes, standard recipes found more suitable for bleaching process.

\section{Conclusions}

Reference to results and discussions, which refers various parameters in peroxide bleaching process, the following general variables is considered to be important while drawing the reliable conclusions on from studies.

\section{Effect of time of bleaching process on whiteness and weight loss}

The time required to bleach with hydrogen peroxide depends on temperature, class of fiber and equipment used for bleaching. In general, the time of bleaching is inversely proportional to the temperature of the bleaching bath. As increases the temperature the rate of bleaching is increases \& correspondingly reduction in process time. Recipes' no III shows the properties optimum weight loss and whiteness as compared to standard $[7,8]$.

\section{Effect of concentration of hydrogen peroxide on whiteness and weight loss}

The optimum concentration of hydrogen peroxide depends on number of factors namely liquor ratio, temperature and class of fiber. In general the time of bleaching is inversely proportional to the concentration of the bleaching bath. As concentration of hydrogen peroxide increases from $2 \mathrm{gpl}$ to $2.5 \mathrm{gpl}, 3 \mathrm{gpl}$ whiteness increases and weight loss is also increases compared to standard. But recipe-I recorded optimum whiteness and weight loss.

\section{Effects of stabilizers on hydrogen peroxide bleaching}

The process of regulation or control of per hydroxyl ion to prevent rapid decomposition of bleach and to minimize fiber degradation is described as stabilization. Stabilizers for peroxide normally function by controlling the formation of free radicals. In general, the concentration of peroxide stabilizer is inversely proportional to the whiteness and directly to weight loss. Sodium silicate is the most conventional, easily available and widely used stabilizer. Sodium silicate is mildly alkaline in nature. Sodium silicate forms a complex compound with per hydroxyl ions which are liberated slowly at higher temperature during bleaching process.

\section{Effects hardness of water on whiteness and weight loss}

Among the all recipes 200 ppm shows high weight loss and low whiteness that is due to hardness of water increases, rate of peroxide decomposition are increases. In general it was observed that as hardness of water inversely proportional to whiteness and directly proportional to weight loss.

\section{References}

1. Shenai VA (1991) Technology of Bleaching and Mercerizing. Sevak Publications (2nd Edn.), New Delhi, India.

2. Shore J (2002) Colourant \& Auxiliaries. Woodhead Publishing Limited, Hampshire 2: 602-607.

3. Sarvanan D, Ramchandran T (2010) Bleaching of cotton fabrics using hydrogen peroxide produced by glucose oxidase. Indian J Fibre Text 35: 281-283.

4. Jones BM, Langlois GW, Sakaji RH (1985) Effect of ozonation and UV irradiation on biorefractory organic solutes in oil shale retort water. Environ Prog 4: 252-258.

5. Changhai Xu, David H, Ahmed El-Shafei, Peter HM, Mary A, Katelyn L (2011) Review of Bleach Activators for Environmentally efficient bleaching of textiles. J Fiber Bioeng Informat 4: 209-219.

6. Broadbent AD (2001) Basic Principles of Textile Coloration. Society of Dyers and Colourists, Woodhead publishing Limited, UK.

7. Cotton Preparation Manual. Sarex, Mumbai, India

8. Rastar A, Hoseinpour A (2011) Simultaneous Dyeing and Bleaching of Cotton Materials. World Applied Sciences Journal 14: 1186-1189. 